\title{
- Case Report
}

\section{Bilateral fusion of permanent canine and lateral incisor}

\author{
VP Singh ${ }^{1}, \mathrm{~S}_{\text {Dhital }}^{2}$, TP Shankar Babu ${ }^{3}, \mathrm{M} \mathrm{Agarwal}^{4}$ \\ ${ }^{1}$ Assistant Professor, Department Of Orthodontics and Dentofacial Orthopedics, ${ }^{2}$ House Officer, \\ Department Of Pediatric Dentistry, ${ }^{3}$ Assistant Professor, Department Of Periodontics, ${ }^{4}$ Assistant \\ Professor, Department Of Conservative dentistry \& Endodontics \\ College of Dental Surgery, BP Koirala Institute of Health Sciences, Dharan, Nepal
}

\begin{abstract}
Fusion is described as the union of two or more tooth buds. It is characterized by a reduced number of teeth, when fused tooth is counted as one. The prevalence of fused teeth in primary dentition is below $1 \%$ and even more less in permanent dentition. The occurrence of fusion in primary dentition may be followed by dental anomalies in permanent dentition. This case report presents a case of bilateral fusion of lateral incisor and canine in primary dentition which was followed by similar fusion in permanent dentition. The aim of this report is to highlight the rarity of such condition by virtue of the number of such cases reported in literature and to evaluate their pulpal morphologies to understand the type of fusion and presence of any other associated pathologies.
\end{abstract}

Keywords: dental anamoly, fusion, gemination

\section{Introduction}

Dental fusion (fusio dentes, dentes confusi, dentes fusi, synodonthia) is a rare developmental anomaly which is, according to Neville's ${ }^{1}$ classification of dental anomalies, included in the anomalies of tooth size. It is defined as a joining of two separate tooth buds during odontogenesis at the time when the crown is not yet mineralized, and depending on the developmental stage in which it occurs, it can be complete or partial. ${ }^{2,3}$ Fusion can occur at the level of enamel or enamel and dentin, which results in the formation of one clinically enlarged crown. Fused teeth can have separated pulpal space, one pulp chamber and two canals or take the form of a large bifid crown with one pulpal space. It is hard to differentiate between fusion and gemination, especially if the supernumerary tooth bud is fused with the adjacent one. ${ }^{4}$ Incidence of fusion depends on race, gender and location.

Address for correspondence:

Dr. Varun Pratap Singh, Assistant Professor

Department of Orthodontics and Dentofacial Orthopedics

College of Dental Surgery, BP Koirala Institute of Health

Sciences, Dharan, Nepal

Email: varundc@gmail.com
According to the available literature its value ranges from $0.2-2.5 \%$ and is more common in primary dentition. ${ }^{5-11}$ This case report presents a rare case of bilateral fusion of permanent lateral incisor and canine. The purpose of this article is to highlight the rarity of the condition and to evaluate the presence of any associated pathology.

\section{Case report}

A 12 year-old girl reported to the Department of Orthodontics and Pediatric Dentistry with the complaint of having large teeth within her lower jaw. Her medical history was irrelevant with her condition.

Intraoral examination revealed bilateral presence of unusually large teeth in the lower right and left lateral incisor and canine region. The two sites were strongly suggestive of conjoined permanent lateral incisors and canine teeth [Figure 1]. Deep labio-lingual groove was associated with the enlarged teeth.

Radiographic evaluation of the side revealed fused 32, 33, 42 and 43 and two distinct roots and single pulp chamber and root canal were evident. [Figure 2]. 


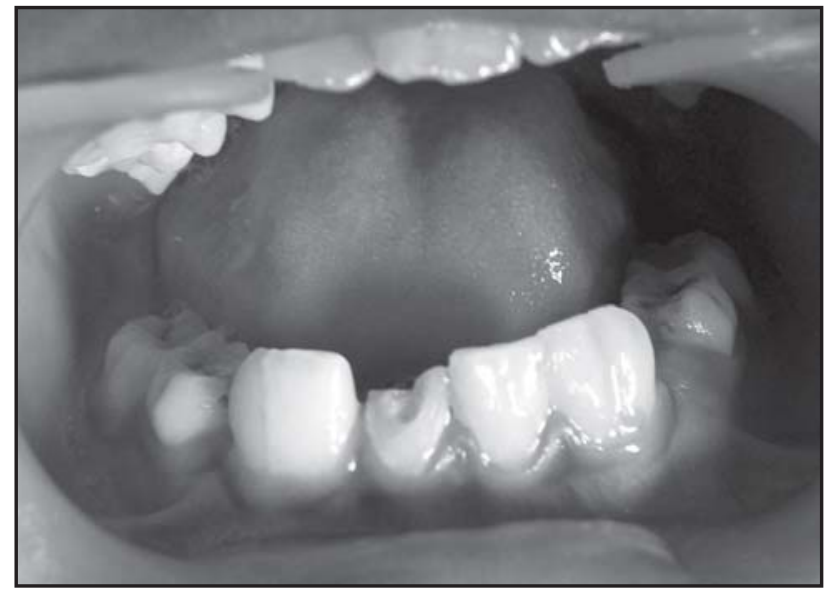

Fig. 1 Intraoral view showing bilateral fusion of mandibular permanent lateral incisor and canine.

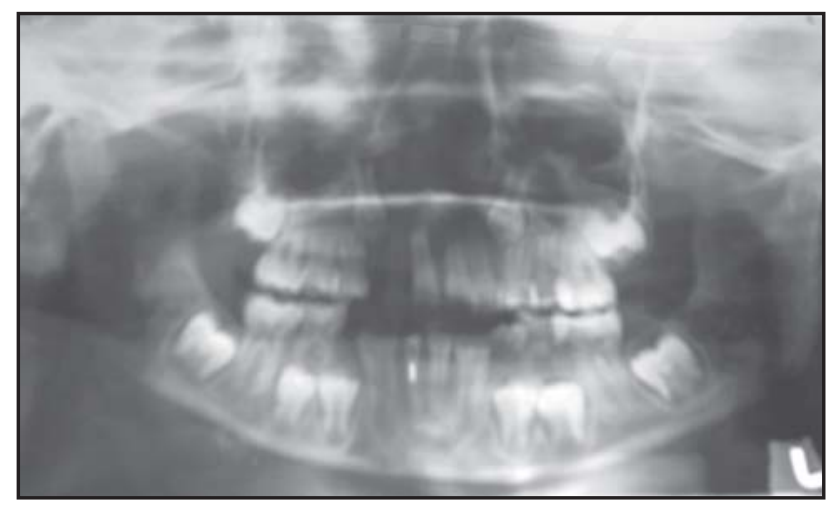

Fig. 2 Panoramic view

The other permanent mandibular frontal teeth were evident, confirming that it was a case of fusion and not gemination. No other associated dental anamoly was detected clinically and radiographically, although the upper canines have not erupted and there is no space in the arch for eruption of upper left canine. An orthopantomograph revealed normal dentition both morphological and numerological. The girl's parents gave history that the girl had the same alteration in her primary dentition and the double tooth was removed due to an eruption delay of the permanent tooth. According to the girl's parents the fused primary teeth has been situated on the same position like the permanent fused teeth.

The patient was diagnosed to be a case of bilaterally fused mandibular permanent lateral incisors and canine tooth of the incomplete type.

\section{Discussion}

It has been thought that some physical force or pressure produces contact between developing teeth resulting in their subsequent fusion. It can occur between normal teeth or between normal and supernumerary teeth. ${ }^{4}$

Fusion can be classified into two types, Complete and Incomplete $^{12}$. They can be differentiated as in [Table $1]$.

Table 1: Differences between complete and incomplete fusion ${ }^{12}$

\begin{tabular}{|c|c|}
\hline Complete & Incomplete \\
\hline $\begin{array}{c}\text { Fusion begins before } \\
\text { calcification. }\end{array}$ & $\begin{array}{c}\text { Fusion occurs at a later } \\
\text { stage. }\end{array}$ \\
\hline $\begin{array}{c}\text { The crown incorporates } \\
\text { features of both } \\
\text { participating teeth with } \\
\text { regard to their en amel, } \\
\text { dentin, cementum, and } \\
\text { pulp. }\end{array}$ & $\begin{array}{c}\text { The tooth might exhibit } \\
\text { separate crown s and fusion } \\
\text { alone limited to the roots } \\
\text { fused or separate. }\end{array}$ \\
\hline
\end{tabular}

The presence of fissures or grooves at the union between fused teeth predisposes it to caries and periodontal disease. ${ }^{13}$ The greater root surface area of fused primary teeth may delay its resorption in case of deciduos dentition. ${ }^{14}$

Fused teeth may also contribute to esthetic concerns, space problems, occlusal disturbances, and delayed eruption of the permanent successors. Hence, careful monitoring of the condition is recommended.

\section{References}

1. Neville BW, Damm DD, Allen CM, Bouquot JE, editors. Abnormalities of teeth. In: Oral and Maxillofacial Pathology. 2-nd ed. New Delhi: Elsevier; 2005. p. 49-106.

2. Dunkan WK, Helpin ML. Oral Surg Oral Med Oral Pathol 1987;64:82-7.

3. Guimarães Cabral LA, Firoozmand LM, Dias Almeida J. Double teeth in primary dentition: Report of two clinical cases. none Med Oral Patol Oral Cir Bucal 2008;13:E77-80.

4. Rajendran R. Developmental disturbances of oral and paraoral structures. In: Rajendran R, Sivapathasundharam B, editors. Shafer's Textbook 
of Oral Pathology. 5 th ed. New Delhi: Elsevier; 2006. p. 3-112.

5. Tinn CA. Excess, deficiency and gemination in the deciduous and permanent dentition of school children. Br Dent J 1940;68:236-8.

6. Menczer LF. Anomalies of the primary dentition. J Dent Child 1955;22:57-62.

7. Munro D. Gemination in the deciduous dentition. Br Dent J 1958;104:238-40.

8. Brook AH, Winter GB. Double teeth. Br Dent J 1970;129:123-30.

9. Ravn JJ. Aplasia, supernumerary teeth and fused teeth in the primary dentition. Scand J Dent Res 1971;79:1-6.

10. Hagman FT. Fused primary teeth: A documented familial report of case. ASDC J Dent Child 1985;52:459-60.
11. Hagman FT. Anomalies of form and number, fused primary teeth, a correlation of the dentitions. ASDC J Dent Child 1988;55:359-61.

12. Rao A. Synodontia of deciduous maxillary central and lateral incisors with a supernumerary tooth. JISSPD. 2000;18(2): 71-74.

13. Nunes E, de Moraes IG, de Oliviera Novaes PM, de Sousa SMG. Bilateral fusion of mandibular second molars with supernumerary teeth: Case Report. Braz Dent J 2002;13:137-41.

14. Brook AH, Winter GB. Double teeth. A retrospective study of 'geminated' and 'fused' teeth in children. Br Dent J 1970;129:123-30. 